\title{
Utilidad de los textos literarios en la docencia de ciencias de la salud: ejemplos en cardiología
}

\author{
Josep Eladi Baños, Elena Guardiola
}

Resumen. La importancia de las humanidades en la educación médica es un hecho generalmente aceptado y se ha sugerido su introducción en los planes de estudio de cursos como los basados en literatura y medicina. A pesar de su viabilidad, existen dificultades en incluir asignaturas específicas en currículos ya apretados. Se ha planteado la posibilidad de utilizar textos literarios como elementos docentes en las asignaturas tradicionales. Sin embargo, existen pocas publicaciones que analicen la utilidad potencial de algunos de ellos. En el presente artículo se presentan tres obras que podrían emplearse para ilustrar la experiencia de la enfermedad en el caso de las cardiopatías. Se escogieron dos textos autobiográficos, Un infart de miocardi, de Josep Pla, y Monte Sinaí, de José Luis Sampedro, y uno de ficción, Mémoires d'Hadrien, de Marguerite Yourcenar. Se revisaron para constatar que podían contribuir a comprender la vivencia de la enfermedad por los pacientes y alcanzar los objetivos educativos establecidos. Se presentan los fragmentos escogidos para ilustrar las repercusiones de la enfermedad y se debate la utilidad para la comprensión de los aspectos emocionales de la enfermedad y de la relación médico-paciente.

Palabras clave. Aspectos emocionales. Docencia. Literatura. Relación médico-paciente.

\section{Usefulness of literary texts in the teaching of health sciences: examples in cardiology}

Summary. The importance of humanities in the medical training is commonly recognized and it has been suggested that its implementation in the medical curricula as literature and medicine courses. In spite of its viability, there is often difficult to include specific subjects in the already crowded medical curricula. Therefore, it has been suggested the use of literary texts as a teaching tool in traditional subjects. However, there are few publications that analyse the potential usefulness of them. In the present paper three literary works that might be used to illustrate the experience of disease in cardiology are discussed. Two autobiographical texts, Un infart de miocardi of Josep Pla and Monte Sinaí of José Luis Sampedro, and a fiction work, Mémoires d'Hadrien of Marguerite Yourcenar, were chosen. They were reviewed to establish their usefulness to understand the patient's experience of disease and to reach educative objectives. The paper shows the chosen fragments to illustrate the disease consequences and its usefulness to understand emotional aspects of sickness and the patient-physician relationship is discussed.

Key words. Emotional aspects. Literature. Patient-physician relationship. Teaching.

\section{Marco conceptual}

La vinculación entre literatura y medicina viene de lejos [1]. De hecho, muchos médicos de todas las épocas se han dedicado a la literatura de forma más o menos intensa. Algunos incluso son más conocidos por su obra literaria que por su actividad médica y constituyen un grupo de profesionales cuyo interés por las actividades humanísticas es destacable. Desde hace algunos años se ha planteado que tal interés no es accidental y se debe a una estrecha relación entre la actividad profesional de los médicos y las características de la propia literatura [2].

En este contexto, el escritor no médico es también una figura importante: percibe la cultura, los valores y distintas formas de ver la medicina en el momento en que crea su obra. Aborda tanto aspectos positivos como negativos y plasma la imagen que la sociedad tiene del médico y de las enfermedades, de una manera especialmente interesante cuando el escritor es, al mismo tiempo, el paciente que muestra su propia vivencia de la enfermedad [3]. Es evidente que el conocimiento de los hechos más críticos de la vida, entre los que destacan las enfermedades y la muerte, son de particular interés para los escritores; por este motivo, mientras que podría decirse que el acto médico es, casi por definición, de interés literario, hay páginas literarias que equivalen a un acto médico [4]. La medicina aparece como motivo literario en cuanto se trata
Departamento de Ciencias Experimentales y de la Salud. Universitat Pompeu Fabra. Barcelona, España.

Correspondencia: Dr. Josep Eladi Baños. Departamento de Ciencias Experimentales y de la Salud. Universitat Pompeu Fabra. Parc de Recerca Biomèdica de Barcelona. Doctor Aiguader, 88. E-08003 Barcelona.

E-mail: josepeladi.banos@upf.edu Conflicto de intereses: No declarado.

Competing interests: None declared.

(c) 2015 FEM 
del drama de la vida, del sufrimiento del ser humano, del dolor físico, del dolor emocional, del dolor social y del temor a la ausencia y a nuestra propia muerte [5].

Se ha sugerido que la literatura puede ser un elemento a considerar dentro de las actividades docentes de los estudiantes de medicina [6-10]. Osler ya aconsejaba la lectura literaria como una forma de mejorar el ejercicio de la medicina por parte de los médicos [11], pero también gana terreno la creencia de que puede ayudar a los estudiantes de medicina en la comprensión de lo que significa ser médico [12]. Obviamente no es un tema en el que haya unanimidad [13], pero existen suficientes evidencias para considerar su aplicación. Así, se argumenta que la introducción de las humanidades médicas, en especial de la literatura, en los estudios de medicina incrementa una serie de capacidades del futuro médico porque auxilia con lecciones concretas sobre la vida de las personas enfermas, permite percibir el poder y las implicaciones de la propia práctica clínica, ayuda a entender mejor el efecto de la enfermedad sobre el paciente, proporciona una mayor comprensión de las experiencias y la vida de los pacientes, contribuye al planteamiento y resolución de conflictos éticos y ofrece nuevas perspectivas en el ejercicio de la práctica clínica [3,14-18].

Una de las dificultades prácticas del empleo docente de la literatura es la definición del lugar que debe ocupar en los planes de estudio. Aunque existen experiencias sobre la implementación de asignaturas específicas de literatura y medicina $[6,12,19$, $20]$, otra posibilidad sería incluir los textos literarios dentro de las actividades regulares de las asignaturas tradicionales. Con ello, podría existir una mejor contextualización de lo que se pretende ofrecer a los estudiantes, se evitaría la segregación en asignaturas separadas y, en el peor de los casos, su marginalización.

En cualquiera de las dos opciones citadas, la selección de los textos literarios que se van a utilizar en este tipo de actividad docente es una decisión capital. A pesar de que las sugerencias de las obras que se pueden emplear llenan los artículos de los que defienden su empleo, es poco frecuente encontrar textos que se hayan analizado de forma adecuada para avalar su empleo docente y que permitan definir objetivos educativos preestablecidos [21$24]$. En este artículo se presentan tres textos literarios y se analiza el interés que pueden tener en la docencia de ciencias de la salud para comprender la respuesta de los pacientes a tres enfermedades cardíacas distintas.

\section{Selección de los textos}

Se seleccionaron tres textos, dos del ámbito de la autobiografía y otro de la literatura de ficción [2527]. Los textos se escogieron después de determinar que reunían las características suficientes para ser utilizados en docencia. Se consideró relevante para ello que los autores no tuvieran vinculación con las profesiones sanitarias y que los textos tuvieran la suficiente concreción para permitir su lectura en poco tiempo, que ilustraran claramente sobre las enfermedades motivo de estudio y que reunieran los principales elementos biológicos y psicológicos para una comprensión holística de la enfermedad. También se valoró el idioma original de publicación o que se dispusiera de una traducción al castellano para facilitar su empleo en nuestro medio.

\section{Un infart de miocardi}

El escritor ampurdanés Josep Pla (1897-1981) es uno de los mejores prosistas en lengua catalana del siglo xx. Combinó el periodismo con el dietario y el ensayo, y tiene también una extensa obra memorialista. Fumador empedernido, bebedor complaciente y amante de la buena mesa, sufrió un infarto de miocardio en 1972 que describió con todo lujo de detalles en un pequeño ensayo con el nombre de esta afección cardíaca.

Pla atribuye a los médicos que le atendieron la génesis del relato que incluyó en un volumen denominado Notes per a Sílvia (1973) [25]. Escrita originalmente en catalán, se utilizó la traducción al castellano de esta obra [28].

\section{Monte Sinai}

Al contrario que Pla, José Luis Sampedro (19172013) no era escritor de profesión. Cursó estudios de economía y a esta área dedicó gran parte de su vida. Sin embargo, siempre estuvo interesado por la literatura y, aunque publicó diversas novelas desde 1952, el éxito le llegó con La sonrisa etrusca en el año 1985.

Mientras se encontraba en Nueva York visitando a su hija, Sampedro sufrió una grave endocarditis que obligó a su hospitalización en el Mount Sinai Hospital de aquella ciudad. En un relato corto con el nombre del centro, publicado dentro del volumen Fronteras (1996), explicó todo lo que significó su estancia hospitalaria, así como las reflexiones derivadas de la amenaza vital que le supuso la enfermedad y sus complicaciones. Se utilizó la publicación independiente de este relato de 1998 [26]. 


\section{Mémoires d'Hadrian}

La escritora belga Marguerite Yourcenar (1903-1987), alias de Marguerite de Crayencour, cultivó la novela histórica con una mezcla de realismo e imaginación. Escribió esta obra sobre el emperador romano Publio Elio Adriano (76-138) en 1951. En ella, el emperador narra en primera persona sus reflexiones sobre la vida cumplidos los 60 años. Adriano sufría insuficiencia cardíaca (hidropesía de corazón, en palabras suyas) y en las primeras páginas de la obra describe los trastornos físicos y psicológicos que le produce esta enfermedad [27]. Escrita originalmente en francés, se utilizó la traducción al castellano de Julio Cortázar [29] y se seleccionaron los capítulos más relevantes y vinculados con la descripción de la enfermedad del emperador.

\section{Análisis textual}

\section{Un infart de miocardi}

En la noche del 17 de agosto de 1972, Pla empieza a sentirse mal después de un día que califica de normal. En su relato, Pla explica los antecedentes inmediatos, que incluyen una cena ligera y ningún tipo de abuso dietético, físico o emocional. Cuando se acuesta, a la una de la madrugada, Pla empieza la lectura habitual, pero comienza a sentirse mal. En sus palabras:

'Al poco de estar tendido, con el libro en la mano, noté que en la parte alta del pecho se me formaba como una especie de barra muy dolorosa, encima mismo de la zona del corazón, y que en la parte posterior del torso se me formaba otra barra paralela y $\tan$ dolorosa como la anterior. Al principio este dolor no fue muy fuerte, sino vago y como mitigado. [...] El dolor se acentuó rápidamente con la aparición encima del esternón, de una forma de dolor más opresiva, de límites triangulares: triángulo invertido con la base en la nuez de Adán y la punta del vértice colocada en la barra delantera del tórax. Mientras, empezaron a dolerme las articulaciones de los brazos, sobre todo la articulación central, la que une el bíceps con el antebrazo y las articulaciones de las manos.

Pla continúa su relato centrándose en el dolor, que es lo que más le preocupa en esos momentos. Procede a definirlo de forma más precisa, señalando que se centra en un punto determinado y cambia de calidad, pasando a ser un dolor más opresivo y no encuentra manera de aliviarlo. Pronto los problemas se agravan con la aparición de sudoración, lo que le lleva a una reflexión sobre la sensación que le produce la enfermedad:

'Cuando el dolor alcanzó determinado nivel, empecé a sudar. En realidad, todo mi cuerpo empezó a sudar. [...] Estando ya en el sudor intenso, me pareció que mi cuerpo empezaba a defenderse. Digo, simplemente, que me lo pareció.'

La persistencia de la sudoración empieza a preocupar seriamente a Pla, especialmente cuando el dolor se va agudizando. Pla pasa toda la noche observándose y esperando mejorar. Por la mañana, con el movimiento de personas en la casa, pide a uno de los mozos que, una vez acabado el trabajo, pidan a su médico que venga a verle. Cuando éste llega:

'El doctor Fuster llegó a primeras horas de la mañana. Me tomó la presión. Luego me dio una inyección considerable de opio sintético -yo tenía un aspecto devastado- que al cabo de cinco minutos rebajó mi dolor de manera notoria.'

El doctor Fuster decide realizar un electrocardiograma y una analítica. El médico que le practica el primero confirma la presencia de un infarto de miocardio en la cara posterior. Otro médico amigo de Pla, el doctor Alsina y Bofill, le aconseja el ingreso en la Clínica Corachán de Barcelona, a donde se traslada en el coche particular de sus amigos, el matrimonio Vergés. Inicia el proceso de recuperación bajo la supervisión de los profesionales del centro. Pla se convierte en un enfermo obediente. Así describe su primera semana en la clínica:

'En la clínica pasé la primera semana en un estado de disciplina total. Jamás había estado en una situación parecida. Tengo la impresión de que fue una novedad tal para mi organismo que no me di cuenta de nada: ni de las inyecciones que me dieron, tan bien dadas; ni de las pastillas que tomé, ni de las extracciones de sangre, ni de los electrocardiogramas, ni de las vitaminas, ni de lo que comí [...]. Quizá lo peor del infarto de miocardio sea el miedo cerval que produce. Todo cuanto puede pasar en el corazón puede ocasionar la muerte.'

Cuando ya acaba su recuperación y se halla cercano al alta hospitalaria, el médico le pregunta sobre lo que ha echado a faltar durante su ingreso. Pla refiere sólo una cosa: el tabaco. Una vez recuperado del 
Tabla I. Algunos objetivos educativos que pueden plantearse con Un infart de miocardi.

Definir la sintomatología del infarto de miocardio según el paciente

Conocer la importancia de los diferentes síntomas para el paciente

Debatir los factores que pueden predisponer a sufrir un infarto de miocardio

Comentar el tratamiento agudo y de mantenimiento del infarto

Debatir cómo los pacientes interpretan las instrucciones del personal sanitario

Conocer la vivencia personal del episodio de infarto de miocardio

Debatir las dificultades en el cumplimiento del tratamiento médico después del episodio agudo

Analizar los consejos que el autor da sobre cómo evitar un infarto de miocardio

episodio agudo, Pla señala cuál es su opinión sobre la enfermedad que acaba de afectarle:

'El infarto de miocardio produce en toda persona medianamente consciente - no creo que podamos pasar de este punto- un miedo cerval. Acobarda, acojona -por decirlo popularmente-. Hay personas que quedan reducidas, asustadas, que quedan como un papanatas, trémulas, imbecilizadas. No fue exactamente este mi caso.'

En la última parte del relato, Pla se hace la pregunta capital para él tras la fase aguda de la enfermedad de qué debe hacer en el futuro y realiza una enumeración de cómo su vida puede quedar afectada por la enfermedad que acaba de sufrir. Considera que no podrá seguir trabajando como antes, que el reposo que le han prescrito será difícil de cumplir, lo difícil que le será dejar el café y el alcohol y, especialmente, el tabaco. Pla vincula el empleo del tabaco con su forma de escribir y argumenta la dificultad que su supresión comportaría en su actividad literaria:

'Ahora me ordenan que deje de fumar. Muy bien. Intentaremos dejar de fumar: la decisión es difícil, pero intentaremos dejar de fumar. Ahora bien, ¿cómo quedará mi literatura sin pausa, más bien meditada, aun habiendo alcanzado cierta facilidad, esta literatura que ustedes creen que es espontánea pero no lo es? -en realidad es todo lo contrario-; ¿cómo quedará mi literatura, abandonada a los adjetivos espontáneos, es decir, profundamente repetidos, vulgares y adocenados? Pero no hay más remedio, la arteriosclerosis no tiene entrañas.'
Las últimas páginas son un recuento de todo lo que ha vivido en el año transcurrido desde el episodio de infarto, con una serie de recomendaciones para evitar sufrirlo de nuevo:

'En primer lugar, hagan lo imposible para no tener deuda alguna. El corazón no tiene nada que ver con los bancos ni con los establecimientos de crédito [...]. No coman demasiado - sin llegar a destruir las reservas naturales- [...]. No entren jamás por gusto en una farmacia. Entren si no les queda más remedio - para arreglar algún dolor desagradable- [...]. Procuren tener alguna forma de riqueza, pero no conviertan esta monstruosidad en una locura. Si la convierten en una locura, sus preocupaciones aumentarán y su vida será miserable [...]. No tengan trato alguno, ni físico ni mental, con ninguna mujer. Me refiero ahora especialmente a las personas que han entrado en el retour d'âge, que es la época más peligrosa de la vida [...]. No se depriman. No se amilanen. Aféitense todos los días. Vistan con naturalidad, conserven las cosas de casa, no malversen, nunca gasten más de lo que tienen realmente. Dialoguen con la gente, tengan curiosidad. No se abandonen, no se recluyan. Lleven una vida normal [...]. Descansen. Hagan reposo. Túmbense en la cama, miren al techo, lean algún libro aburrido que se les caiga de las manos.'

Pla acaba con una declaración poco positiva con el cumplimiento terapéutico aconsejado por sus médicos:

'Al salir de la clínica los médicos me dijeron: «Pasee por el campo, en un terreno llano». No lo he hecho [...]. Me dijeron: « $N o$ fume!». He fumado mi tabaco habitual: Ideales. Con mi papel, de cada cigarrillo he hecho dos, y un paquete me ha durado dos o tres días [...]. También me dijeron: «Tome un poco de whisky, pero con calma». Es lo que he hecho.'

La tabla I recoge algunos de los objetivos educativos que pueden plantearse en actividades docentes que utilicen esta obra de Pla.

\section{Monte Sinaí}

La obra de Sampedro se inicia con la descripción de su ingreso en la unidad de vigilancia intensiva (UVI) del Mount Sinai Hospital de Nueva York, como consecuencia de haberse sentido mal mientras visi- 
taba a su hija. La razón se explica en las primeras páginas:

'Mi enfermo corazón, cuyas arritmias, soplos y desaforadas distonías habían alarmado a nuestro médico de cabecera hasta el punto de apresurar mi hospitalización. Mi hija, caminando al lado de mi vehículo, compartía esos temores, pero en cambio mi estado de ánimo durante la travesía, bajo las luces subterráneas de neón, era ajeno a toda inquietud y se remansaba en una sosegada curiosidad. Ni siquiera la idea de que a ella le costaba trabajo disimular -se me ocurrió alguna vez, lo recuerdo muy bien- despertó en mí el menor desasosiego. «Debo estar muy débil», recuerdo haber pensado, mientras seguía dejándome llevar. «Dejándome llevar», esa era la más cabal expresión de mi indiferente desasimiento en aquellos instantes.'

En el relato, escrito cuando Sampedro ya ha regresado al domicilio de su hija, reflexiona sobre los momentos previos al ingreso en la UVI:

'Sigo sin comprender aquella actitud mía, pues la debilidad tras varios días con fiebre no es una explicación suficiente [...]. ¿Saldré de él con vida?, me pregunté alguna vez, pero como si la cosa no fuera conmigo, y a la curiosidad por mi futuro inmediato se añadía la sorpresa ante mi insensibilidad y mi falta de reacción [...]. Era como si ese otro yo, con quien a veces siento vivir emparejado, el escritor, se hubiese disociado de mi ser enfermo'.

Sampedro insiste en sus sensaciones y recuerdos durante los días que permaneció en la UVI:

'Aquellos tres primeros días... pero, ¿cabe llamarlos «días»? ¿No fueron más un paréntesis, tiempo de otro calendario? Mis recuerdos de entonces desafían todo intento cronológico; mi sensación dominante es la de flotar al capricho del viento y de la marejada. Tan pronto estaba tapado como semidesnudo, yacente como incorporado, en mi cama o rodando hacia un electro o un ecocardiograma. Retengo todo un tropel de operadores: médicos, asistentes o enfermeras, cediéndose mi cuerpo de unos a otros para tomarme la tensión, administrarme pastillas, registrar mi temperatura, inyectarme algo, pincharme en otra vena $\mathrm{o}$, simplemente, asomarse a examinar las picudas y movedizas líneas en mis pantallas.'
Durante su hospitalización, Sampedro presenta complicaciones que le causan una profunda inquietud:

'Cuando anoche no me he muerto es que ya no me muero, por ahora. Esas palabras son la única nota de mis papeles el día 18 de mayo, escritas en una letra más temblorosa todavía que en días anteriores. No hacía falta escribir más para asegurar el recuerdo, pues no podré olvidar nunca esa noche [...]. A la noche sufrí el castigo impuesto a mis ilusiones, aun siendo involuntarias, a mis sueños de lechera confiada. Dormía plácidamente $y$, de pronto, se desató la violencia. Unos asaltantes me zarandeaban y antes de casi abrir los ojos me descubrí sentado en la cama por la fuerza. Protesté iracundo: «iEstoy bien, déjenme dormir!», pero fue inútil. Sentí el pinchazo de una inyección, me vi rodeado por cinco personas agitadas, me parecieron sayones, recordé las detenciones de madrugada, «¿me sacan de aquí?, ¿qué pasa?». Nadie explicaba nada. Hablaban entre sí, no les entendía, en la puerta un hombre joven parecía dirigir la súbita agresión. Me quitaron la túnica del uniforme, reclamé la presencia del doctor Verdaguer, de la doctora Vane: ni me escuchaban. Sentí algo pegajoso y frío aplicado contra la espalda y, en seguida, idéntica aplicación sobre mi pecho: un cuadrado metálico como una loseta, sujeto por el pegamento habitual. Me agitaba entre la ira y la desesperación. «iSólo necesito dormir! ¡Protesto de este atropello!». De la placa pectoral salía un cable, iban a aplicarme algo nuevo, una consolita traída a traición durante mi sueño. El jefe se acercó a ella y manipuló unos mandos. «AAy!» grité al sentir en el pecho un puñetazo dejándome sin aliento: una descarga eléctrica entre las dos placas. Me desplomé de espaldas en la cama mientras ellos me contemplaban en corro. Ya lo habían conseguido; otra descarga me sacudió el torso y me arrancó un gemido. Pensé en los electroshocks a los psicópatas, en la «picana» de los torturadores argentinos [...]. ¿Por qué a mí? [...]. El jefe y sus hombres se retiraron, sólo quedó una enfermera, la que me había inyectado. Me fijé en ella, una mujer de color, gruesa, de mediana edad. Debió de percibir la angustia en mis ojos, mirada de animal en matadero, porque tomó mi mano entre las suyas y empezó a hablarme en español. Su voz salía con sosiego de entre sus dos mejillas, rostro a la vez risueño y grave, explicándome que mientras yo dormía mi corazón se dejaba caer hacia su final... Por fortuna, mis cinco electrodos alertaron en las panta- 
Tabla II. Algunos objetivos educativos que pueden plantearse con Monte Sinaí.

Definir la sintomatología de la endocarditis

Analizar los factores de riesgo de la endocarditis

Debatir la vivencia de la hospitalización del autor

Interpretar el episodio de reanimación cardíaca en la unidad de cuidados intensivos

Debatir las consecuencias psicológicas de la enfermedad y de sus secuelas

llas del cuarto de guardia, el médico envió al grupo, las descargas en mi pecho sostenían el corazón mientras actuaba el fármaco [...]. La explicación me solidarizaba agradecido con mis asaltantes y la mano rolliza de la negra era una caricia: «eso va mejor, niño».

Finalmente, Sampedro supera la enfermedad pero siente las secuelas que le ha dejado. Tras la primera visita de control en el hospital escribe:

'Resulta que he pasado la frontera, la infección y la endocarditis están superadas, pero dejando jirones en la zarza ardiente de la ascensión. Me quedan insuficiencias mayores que antes y le gustaría volver a verme dentro de seis meses, propuesta que he aceptado pues espero retornar como de costumbre a pasar las Navidades con mis hijos y mi nieto.'

A su vuelta a España, Sampedro reflexiona sobre lo que ha supuesto para él la experiencia de su última hospitalización y la apreciación de un posible punto final a su vida:

'No es sensato engañarse: Sinaí ha sido la última frontera; el próximo accidente no desembocará otra vez en mi vida. La muerte, como tantas veces pienso, no es importante para uno sino para quien nos quiere. Para ellos hay que vivir, por ellos no está aún la vida cumplida (como antes pensé) y por ellos hay que seguir viviendo aunque, no nos engañemos, en estado muriente. La muerte es la corona de hierro final, el toque último del hacerse [...]. Sea lo que sea. Corto o largo, fácil o doloroso, hay que vivir el sendero con dignidad. Os daré lo que me queda de lo que soy. Dadme la mano y adelante. En el umbral de los ochenta años ya va siendo hora de empezar de nuevo.'
La tabla II recoge los objetivos educativos que pueden plantearse con el empleo de este relato de Sampedro.

\section{Mémoires d'Hadrian}

Adriano, nacido en Itálica (cerca de la actual Sevilla), sucedió a Trajano como emperador el año 117. Su obra se caracterizó por su espíritu pacificador, lo que llevó a abandonar las campañas de expansión de su predecesor y consolidar las fronteras del Imperio (muro de Adriano). También realizó reformas internas apreciables en el ámbito legislativo con la unificación de normas y la consagración del derecho romano. Las intrigas y la pérdida de salud contribuyeron a amargar la vida de Adriano en sus últimos años. Yourcenar realiza, en esta novela histórica, un excelente fresco del emperador, que se inicia con una reflexión del propio Adriano al cumplir 60 años, cuando la enfermedad ya le limita de forma importante. De hecho, falleció dos años después de la edad que Yourcenar le atribuye en la obra.

En las primeras páginas, el emperador explica el empeoramiento de su salud:

'He ido esta mañana a ver a mi médico Hermógenes [...]. Me tendí sobre un lecho luego de despojarme del manto y de la túnica. Te evito detalles que te resultarían tan desagradables como a mí mismo, y la descripción del cuerpo de un hombre que envejece y se prepara a morir de hidropesía del corazón [...]. Es difícil seguir siendo emperador ante un médico, y también es difícil guardar la calidad de hombre. El ojo de Hermógenes sólo veía en mí un saco de humores, una triste amalgama de linfa y de sangre. Esta mañana pensé por primera vez en mi cuerpo, ese compañero fiel, ese amigo más seguro y mejor conocido que mi alma, no es más que un monstruo solapado que acabará por devorar a su amo. Haya paz [...]. Amo mi cuerpo; me ha servido bien, y de todos modos no le escatimo los cuidados necesarios. Pero ya no cuento, como Hermógenes finge contar, con las virtudes maravillosas de las plantas y con el dosaje exacto de las sales minerales que ha ido a buscar a Oriente. Este hombre, tan sutil sin embargo, abundó en vagas fórmulas de aliento, demasiado triviales para engañar a nadie. Sabe muy bien cuánto detesto esta clase de impostura, pero no en vano ha ejercido la medicina durante más de treinta años. Perdono a este buen servidor su esfuerzo por disimularme la muerte. Hermógenes es sabio, y tiene también la sabiduría de la prudencia: su probidad excede 
con mucho a la de un vulgar médico de palacio. Tendré la suerte de ser el mejor atendido de los enfermos. Pero nada puede exceder de los límites prescritos: mis piernas hinchadas ya no me sostienen durante las largas ceremonias romanas, me sofoco; y tengo sesenta años.'

Este fragmento describe de forma magistral los sentimientos del emperador con el progreso de su enfermedad. La hidropesía del corazón es el nombre clásico de lo que hoy llamamos insuficiencia cardíaca. El texto recoge tres de los datos semiológicos del síndrome: cansancio, disnea y edema en las extremidades inferiores. Además, muestra también algunos de los recovecos de la relación médico-paciente, ilustrados por el deseo de Hermógenes de encubrir una grave realidad que Adriano ya percibe. Más adelante prosigue con este sentimiento de enfermedad incurable:

'Decir que mis días están contados no tiene sentido; así fue siempre; así es para todos. Pero la incertidumbre del lugar, de la hora y del modo, que nos impide distinguir con claridad ese fin hacia el cual avanzamos sin tregua, disminuye para mí a medida de que la enfermedad mortal progresa. Cualquiera puede morir súbitamente, pero el enfermo sabe que dentro de diez años no vivirá. Mi margen de duda no abarca los años sino los meses.'

El libro continúa con la descripción de muchos de los acontecimientos de la vida del emperador hasta que súbitamente, hacia la mitad de la obra, aparece la descripción de cómo se manifestó la enfermedad por primera vez:

'Mi cuerpo me temía; continuamente notaba en el pecho la oscura presencia del miedo, una opresión que no era todavía dolor pero sí el primer paso hacia él. Desde mucho tiempo atrás estaba acostumbrado al insomnio, pero ahora el sueño era aún peor que su ausencia; apenas dormido, me despertaba horriblemente angustiado. Padecía de dolores de cabeza que Hermógenes achacaba al tiempo caluroso y al peso del casco. Por la noche, después de las prolongadas fatigas, me sentaba como quien se desploma; levantarme para recibir a Rufo o a Severo me demandaba un esfuerzo para el cual tenía que prepararme por adelantado. Mis codos me pesaban en los brazos del asiento, y me temblaban los muslos como los de un corredor exhausto. El menor gesto se convertía en una fatiga, y de esas fatigas estaba he- cha la vida. Un accidente casi ridículo, una indisposición de niño, reveló la enfermedad agazapada detrás de aquella fatiga atroz. Durante una reunión tuve una hemorragia nasal de la que me preocupé muy poco, pero que continuó durante la cena; en plena noche me desperté bañado en sangre... Una noche en que, apenas convaleciente, cometía la imprudencia de hacer un breve paseo a caballo, recibí un segundo aviso, más grave aún que el primero. Por espacio de un segundo sentí que los latidos de mi corazón se precipitaban, y que disminuían luego cada vez más hasta detenerse. Creí caer como una piedra en no sé qué pozo negro, que sin duda es la muerte [...]. Hermógenes acabó por diagnosticar el principio de hidropesía de corazón [...]. Me sentía como avergonzado de aquella enfermedad interna, casi invisible, sin fiebre ni abscesos, sin dolores de entrañas, y cuyos síntomas son una respiración algo más forzada y la marca lívida que deja en el pie hinchado la correa de la sandalia.

En la descripción pueden reconocerse algunos datos semiológicos que indicarían la posible existencia de crisis hipertensivas (epistaxis, cefaleas) que podían haber llevado a una cardiopatía hipertensiva. El episodio de taquiarritmia seguido de bradicardia intensa que describe indicaría asimismo una afectación grave del corazón, que se acompañaría ya de edemas en las extremidades inferiores. La enfermedad progresa y comienza a causar una serie de limitaciones físicas que suponen un sufrimiento notable al emperador, de manera que empieza a plantearse el fin de su vida:

'Estoy de acuerdo en morir, pero no en asfixiarme; la enfermedad nos hace sentir repugnancia de la muerte, y queremos sanar, lo que es una manera de querer vivir. Pero la debilidad, el sufrimiento, mil miserias corporales, no tardan en privar al enfermo del ánimo para remontar la pendiente; pronto rechazaremos esos respiros que son otras tantas trampas, esas fuerzas flaqueantes, esos ardores quebrados, esa perpetua espera de la próxima crisis [...]. Funciones que antaño resultaban fáciles y hasta agradables, llegan a ser humillantes cuando se las cumple con dificultad [...]. Volví a sentir la obsesión de la muerte, pero esta vez sus causas eran visibles, confesables, y mi peor enemigo no habría podido sonreír. Nada me retenía ya; hubiera sido comprensible que el emperador, recluido en su casa de campo luego de poner orden en los negocios del estado, tomara las medidas necesarias 
Tabla III. Algunos objetivos educativos que pueden plantearse con Mémoires d'Hadrien.

Definir la sintomatología de la insuficiencia cardíaca

Analizar las consecuencias de la insuficiencia cardíaca en la vida de los pacientes

Debatir los sentimientos de los pacientes frente a una enfermedad crónica y mortal

Analizar los antecedentes que pudieron causar la insuficiencia cardíaca

Debatir el proceso de aceptación de la situación terminal y el desenlace final

para facilitar su fin. Pero la solicitud de mis amigos equivale a una vigilancia constante: todo enfermo es un prisionero. Ya no me siento con fuerzas para hundir la daga en el lugar exacto, marcado antaño con tinta roja bajo la tetilla izquierda [...]. Para preparar mi suicidio necesitaba tomar las mismas precauciones que un asesino para dar el golpe.'

Pero poco más adelante acepta el progreso de la enfermedad y todas sus consecuencias:

'No rehúso ya esa agonía que me corresponde, ese fin lentamente elaborado en el fondo de mis arterias, heredado quizá de un antecesor, nacido de mi temperamento, preparado poco a poco por cada uno de mis actos en el curso de mi vida. La hora de la impaciencia ha pasado; en el punto en que me encuentro, la desesperación sería de tan mal gusto como la esperanza. He renunciado a apresurar mi muerte.'

En las últimas páginas de la novela, el emperador describe la situación terminal y el empeoramiento físico, con la aparición de una molesta ortopnea, así como la resignación y la aceptación del momento que se acerca inevitablemente:

'Mi paciencia da sus frutos. Sufro menos, y la vida se vuelve casi dulce. No me enojo ya con los médicos; sus tontos remedios me han condenado, pero nosotros tenemos la culpa de su presunción y su hipócrita pedantería; mentirían menos si no tuviéramos tanto miedo a sufrir [...]. El porvenir del mundo ya no me inquieta; ya no me esfuerzo por calcular angustiadamente la mayor o menor duración de la paz romana; dejo hacer a los dioses. No es que confíe más en su justicia que no es la nuestra, ni tengo más fe en la cordura del hombre; la verdad es justamente lo contrario. La vida es atroz, y lo sabemos. Pero precisamente porque espero poco de la condición humana, los períodos de la felicidad, los progresos parciales, los esfuerzos de reanudación y de continuidad me parecen otros tantos prodigios, que casi compensan la inmensa acumulación de males, fracasos, incuria y error [...]. Los medicamentos ya no actúan; la inflamación de las piernas va en aumento, y dormito sentado más que acostado. Una de las ventajas de la muerte será estar otra vez tendido en un lecho [...]. Me felicito que el mal me haya dejado mi lucidez hasta el fin; me alegro de no haber tenido que pasar por la prueba de la extrema vejez, de no estar destinado a conocer este endurecimiento, esta rigidez, esa sequedad, esa atroz ausencia de deseos [...]. Todo está pronto; el águila encargada de llevar a los dioses el alma del emperador se halla lista para ser empleada en la ceremonia fúnebre [...]. Tratemos de entrar en la muerte con los ojos abiertos.'

La tabla III recoge los objetivos educativos que pueden plantearse con esta novela de Yourcenar.

\section{Conclusiones}

Las obras comentadas en este artículo presentan tres situaciones distintas que tienen, sin embargo, elementos de interés para la docencia de ciencias de la salud. En primer lugar, describen de manera clara la semiología de las tres afecciones: el infarto de miocardio, la endocarditis y la insuficiencia cardíaca. A través de las palabras propias de Pla y Sampedro y de las interpuestas de Yourcenar, se puede apreciar con claridad cómo se generaron las enfermedades, qué signos y síntomas causaron y las complicaciones que aparecieron en algunos de ellos. Pero aún más importante, los textos muestran siempre la vivencia de la enfermedad en cada paciente, cómo le afecta, qué pensamientos le genera y cómo observa el futuro mientras pasa por ella. Obviamente, las tres situaciones varían en otros aspectos, en especial en el caso del emperador, en el que el relato final acaba con su fallecimiento. Consideramos que estas obras brindan al estudiante la posibilidad de entrar en contacto con el paciente que padece una determinada enfermedad, que la describe con sumo detalle, pero antes de enfrentarse al paciente real; podríamos decir que, en cierto sentido, constituyen un puente entre la teoría y la práctica. Por otro lado, al tratarse de textos que no son largos, se facilita su utilización como material docente dentro de la enseñanza de la patología cardíaca, ya que 
no constituye una sobrecarga excesiva en la siempre amplia carga de lectura que tiene el estudiante de medicina.

¿Qué aporta el presente artículo al empleo de la literatura en la docencia de las ciencias de la salud? En nuestra opinión es uno de los primeros artículos en que no se sugiere exclusivamente el uso de la literatura o de determinados textos literarios, sino que se aportan tres ejemplos vinculados -en este caso- a las enfermedades cardíacas, se comentan los fragmentos de mayor interés y se determinan los objetivos educativos de las actividades que los utilicen. En otras palabras, no se sugiere de forma general que podrían ser útiles, sino que se explica con detalle cómo podrían ser útiles. Así, se propondría su lectura dentro de la asignatura correspondiente (patología médica, cardiología), como complemento al estudio de esas tres enfermedades.

Algunos autores sugieren que, en la formación del médico residente, la medicina basada en pruebas debe ir necesaria y eficazmente unida a la medicina humanística basada en narrativas y valores. En este sentido, Barbado-Hernández [17] ha señalado que la literatura es también un complemento fundamental en la formación del médico que está cursando la especialidad: para adquirir las habilidades clínicas generales -entre las que destaca la capacidad para obtener una buena historia clínica con todos los detalles- y para adquirir habilidades comunicativas. Afirma este autor que la literatura ayuda a conocer las enfermedades desde 'otras miradas'; así, son especialmente interesantes las autobiografías y las memorias, que nos hacen conocer y vivir otras experiencias que enriquecen la nuestra. Coincidimos con estas opiniones y pensamos que también podría ser interesante la utilización de los tres textos que se analizan en el presente trabajo en la formación del médico residente de diversas especialidades (medicina interna, cardiología, medicina familiar y comunitaria).

Queda obviamente pendiente la determinación empírica de tales proposiciones, pero se han puesto las bases para que la determinación de su eficacia sea posible. En cualquier caso, los textos muestran la vivencia de los pacientes con su enfermedad, un aspecto que apenas forma parte de los planes docentes de los estudios de ciencias de la salud. En este sentido, creemos que la literatura puede ayudar de forma importante a que los estudiantes y los médicos residentes comprendan con más facilidad la vivencia de la enfermedad y puedan interpretar situaciones que son difíciles de intuir durante la formación académica y, en muchas ocasiones, también al principio del ejercicio profesional.
Puede argumentarse, con razón, que existen múltiples ejemplos en la literatura universal que podrían emplearse con los mismos objetivos y que la elección de los textos de Pla, Sampedro y Yourcenar es aleatoria. Aceptamos que esta observación constituye una de las limitaciones del artículo, pero la propuesta que se presenta no pretende ser excluyente de otras posibilidades. Existen numerosos ejemplos de obras, escritas por aquellos que han sufrido una enfermedad, que podrían emplearse en la docencia de ciencias de la salud. Al respecto pueden encontrarse ejemplos en enfermedades oncológicas [30-37], neurológicas [38-42] o psiquiátricas [43-49], entre otras. De hecho, esperamos que los lectores se animen a identificar nuevos textos que puedan utilizarse de forma similar a la que proponemos en el mismo $u$ otros ámbitos de las ciencias médicas.

Aunque se ha planteado si los relatos de los pacientes son realmente veraces o tienden a la interpretación personal (excesivamente subjetiva) de lo que les sucede [50], creemos que esta posibilidad no debe menospreciar su importancia, pero sí es necesario tenerla en cuenta al analizar cada situación. Otro problema en la utilización de textos literarios publicados originalmente en otro idioma es la fidelidad o exactitud de las traducciones. $\mathrm{Al}$ comparar la traducción del relato de Pla con el texto original hemos encontrado algunas diferencias -algunas notables, otras de matiz- que, sin embargo, no alteran el sentido del texto teniendo en cuenta el propósito para el que se ha utilizado. Pensamos que esto podría no ser así y tener importancia en el caso de otras obras. Por este motivo, y aunque parece lógico y está ampliamente admitido, debemos aconsejar que se lean, siempre que sea posible, los textos en la lengua en que fueron escritos.

En conclusión, creemos que los textos analizados en este artículo pueden tener interés para que los estudiantes comprendan mejor la experiencia de la enfermedad desde el punto de vista de quien la padece. Si esta asunción es o no cierta, sólo podrá demostrarse con estudios específicos dirigidos a comprobar si se alcanzan los objetivos educativos preestablecidos.

\section{Bibliografía}

1. Neve M. Medicine and literature. In Bynum WF, Porter R, eds. Companion encyclopedia of the history of medicine. Vol. 2. London: Routledge; 1993. p. 1520-35.

2. Navarro FA. Viaje al corazón de uno mismo. ¿Por qué demonios escriben los médicos? Discurso de ingreso en la Asociación Española de Médicos y Artistas (ASEMEYA). Madrid; 1999.

3. Álvarez-Díaz JA. Importancia de la literatura dentro de las humanidades médicas. Gac Med Mex 2010; 146: 71-5. 
4. Díaz JP. Medicina y literatura. Rev Med Uruguay 1994; 10: 5-12.

5. Rillo AG, Vega-Mondragón L. Literatura y medicina. Espéculo: Revista de Estudios Literarios 2009. URL: http:// pendientedemigracion.ucm.es/info/especulo/numero42/ litemedi.html. [24.09.2013].

6. Hunter KM, Charon R, Coulehan JL. The study of literature in medical education. Acad Med 1995; 70: 787-94.

7. McLellan MF, Jones AH. Why literature and medicine? Lancet 1996; 348: 109-11.

8. Calman KC. Literature in the education of the doctor. Lancet 1997; 350: 1622-4.

9. Baños JE. Interés de la literatura en la formación de los estudiantes de medicina. Educ Med 2003; 6: 93-9.

10. Loscos J, Baños JE, Loscos F, De la Cámara J. Medicina, cine y literatura: una experiencia docente en la Universitat Autònoma de Barcelona. Rev Med Cine 2006; 2: 138-42.

11. Osler W. Books and men. In Osler W. Aequanimitas, with other addresses to medical students, nurses and practitioners of medicine. 3 ed. Philadelphia: P. Blakiston's Son \& Co; 1932 p. 209-15.

12. Hawkins $\mathrm{AH}, \mathrm{McEntyre} \mathrm{MC}$. Teaching literature and medicine: a retrospective and a rationale. In Hawkins $\mathrm{AH}$ McEntyre MC, eds. Teaching literature and medicine. New York: The Modern Language Association; 2000. p. 1-28.

13. Bignall J. Literature and medicine. Lancet 2001; 357: 1302.

14. Lorenzo-Cáceres A. Las humanidades en la formación del médico. Tribuna Docente en Medicina de Familia 2002; 3: 3-12.

15. Thernstrom $M$. The writing cure. Can understanding narrative make you a better doctor? New York Times Magazine 2004; Apr 18: 42-7.

16. MacManus IC. Humanity and the medical humanities. Lancet 1995 ; 346: 1143-5.

17. Barbado-Hernández FJ. Medicina y literatura en la formación del médico residente de medicina interna. Ann Med Int 2007 24: 195-200.

18. Craice de Benedetto MA, Gatti G, Lima da Costa D. La literatura como recurso didáctico en la formación humanística de los estudiantes de medicina. Aten Fam 2011; 18: 59-62.

19. Downie RS, Hendry RA, Macnaughton RJ, Smith H. Humanizing medicine: a special module. Med Educ 1997; 31: 276-80.

20. Calman KC, Downie RS, Duthie M, Sweeney B. Literature and medicine: a short course for medical students. Med Educ 1988; 22: 265-80.

21. Jones AH. Literature and medicine: García Márquez' Love in the Time of Cholera. Lancet 1997; 350: 1169-73.
22. Blanco-Venzalá M. Alexitimia, a propósito de un caso... literario. Archivos de Psiquiatría 2003; 66: 77-88.

23. Wasserstein AG. Lessons in medical humanism: the case of Montaigne. Ann Int Med 2007; 146: 809-13.

24. Brungardt $\mathrm{G}$. Teaching The death of Ivan Ilych: a guide to introducing Tolstoy's classic. J Palliative Med 2009; 12: 679-82.

25. Pla J. Un infart de miocardi. In Pla J, ed. Notes per a Sílvia. Obres completes. Vol. 26. Barcelona: Destino; 1974. p. 527-65.

26. Sampedro JL. Monte Sinaí. Barcelona: Plaza y Janés; 1998.

27. Yourcenar M. Mémoires d'Hadrien. Paris: Plon; 1951.

28. Pla J. Un infarto de miocardio. In Pla J, ed. Dietarios II. Notas para Sílvia/Notas del crepúsculo. Madrid: Espasa Calpe; 2002. p. 361-84.

29. Yourcenar M. Memorias de Adriano. Barcelona: Edhasa; 1982.

30. Frouchtmann S. Mi cáncer y yo. Barcelona: Plataforma Editorial; 2009.

31. Suárez M. Diagnóstico: cáncer. Barcelona: Círculo de Lectores; 2000.

32. Coetzee JM. L'edat de ferro. Barcelona: Edicions 62; 2002.

33. Solzhenitsyn A. Pabellón de cáncer. Barcelona: Círculo de Lectores: 1973.

34. Tolstoi L. La muerte de Ivan Ilich. Madrid: Alianza Editorial; 1995.

35. Villatoro V. Moon River. Barcelona: Columna; 2011.

36. Beauvoir S. Una muerte muy dulce. Barcelona: Edhasa; 1989.

37. Lobo Antunes N. Lo siento mucho. Madrid: Aguilar; 2009.

38. Argullol R. Davalú o el dolor. Barcelona: Quaderns Crema; 2001.

39. Bauby JD. La escafandra y la mariposa. Barcelona: Plaza y Janés; 1997.

40. García-Martínez JC. La enfermedad de Parkinson vista por un afectado. Rev Neurol 2003; 37: 391-400.

41. Sacks O. Despertares. Barcelona: Anagrama; 1998.

42. Sacks O. La isla de los ciegos al color y la isla de las cicas. Barcelona: Anagrama; 1999.

43. Bulgákov M. Morfina. Barcelona: Compactos Anagrama; 2002.

44. Chejov A. El pabellón número 6. Madrid: Alianza Editorial; 1979.

45. Shem S. Monte miseria. Barcelona: Anagrama; 2000.

47. Jamison KR. Una mente inquieta. Testimonios sobre afectos y locura. Barcelona: Tusquets; 1996.

48. Styron W. Esa visible oscuridad. Memoria de la locura. Barcelona: Belacqua; 2009.

49. Valère V. Diario de una anoréxica. Barcelona: Plaza y Janés; 1994

50. Shapiro J. Illness narratives: reliability, authenticity and the empathic witness. Med Humanit 2011; 37: 68-72. 